\title{
Spontaneous Unilateral Subperiosteal Hematoma in the Orbit due to Self-Induced Asphyxia: Unusual Cause of Unilateral Exophthalmos
}

\author{
Xavier Subiras Konrad R. Koch Silvia Schrittenlocher Claus Cursiefen \\ Ludwig M. Heindl \\ Department of Ophthalmology, University Hospital of Cologne, Cologne, Germany
}

\section{Keywords}

Subperiosteal bleeding $\cdot$ Orbital bleeding $\cdot$ Valsalva maneuver $\cdot$ Venous pressure

\begin{abstract}
Background: To report an unusual case of subperiosteal bleeding of nontraumatic etiology. Case Description: A 48-year-old female presented with an acute protrusion of the left eye after nonaccomplished suicide by means of asphyxia using a cable around the neck. At the time of presentation, the MRI showed an orbital subperiosteal hematoma causing an exophthalmos. After conservative treatment, there was a complete remission of the lesion. Conclusion: Nontraumatic subperiosteal bleedings without involvement of the intraocular structures and no vision-threatening intraorbital changes should be treated conservatively.
\end{abstract}

\section{Background}

Orbital bleeding tends to be of traumatic etiology. The more uncommon nontraumatic orbital bleedings have been reported due to vascular malformations (normally presenting 
diffuse bleeding). Of bleedings with nontraumatic etiology, subperiosteal bleedings are probably the second most common [1,2]. Here, we present an unusual case of a patient that had a spontaneous subperiosteal hemorrhage due to self-strangulation or, in other words, due to increased intracranial venous pressure.

\section{Case Description}

A 48-year-old female was found at the end of December 2015 lying in her bathtub with a cable around her neck after copious alcohol ingestion. After acute internal and psychiatric evaluation, the patient presented herself a week later in our clinic with painless spontaneous proptosis of $4 \mathrm{~mm}$ of the left globe with downward displacement (Fig. 1a). The visual acuity was $20 / 20$ and the intraocular pressure was $15 \mathrm{~mm} \mathrm{Hg}$. There were no pathological perimetric findings. No afferent pupillary defect and no dyschromatopsia were found. There was little restriction of movement on upward gaze. We also saw a slight hyperemia of the conjunctiva, no petechiae, and a normal funduscopic finding. There was no known systemic disease, specifically, no bleeding disorders, nor was the patient taking anticoagulants.

Magnetic resonance imaging (MRI) revealed a homogenous biconvex lesion (Fig. 2a, b) in the superior left medial orbit without compression of the optic nerve and lying above the superior rectus and superior oblique muscle. We recommended a conservative treatment until the next visit.

During the following weeks, the proptosis decreased gradually. The MRI 4 months after the onset of symptoms showed a complete resolution of the lesion (Fig. 2c, d). On clinical examination, the visual acuity had not decreased, there was no restriction or pain on movement and no afferent defect, and intraocularly, there was a normal finding.

\section{Discussion}

Nontraumatic orbital hemorrhage is rare. This type of bleeding tends to be bound to systemic diseases, localized malformations, neoplasia, infections/inflammations, or simply an increase in venous pressure/intracranial pressure due to Valsalva maneuver [1-3, 5-8]. These can be diffuse, extraperiosteal (rectus sheath muscles) [7], or subperiosteal. Subperiosteal bleedings are the second most common nontraumatic orbital hemorrhages after diffuse bleeding due to vascular malformations.

Bleeding through venous pressure is believed to happen due to rupture of bridging veins crossing the periosteal space $[2,4]$ and the orbital bone. Due to fewer attachment sites between the periosteum and the superior bony orbital wall, blood tends to pool in this area, giving the typical biconvex configuration of a subperiosteal orbital hemorrhage in MRI and computed tomography imaging. Descriptions of these rare bleedings were already present at the beginning of the 20th century by Duke-Elder [4], as it was in the cases of exertion against closed glottis $[4,8]$.

Out of those subperiosteal bleedings due to exercise $[4,8]$ and newborns with complicated delivery (dystocia) [1, 2], one of the most common causes of nontraumatic subperiosteal orbital hemorrhage is vomiting $[1,2]$. The majority of these spontaneous bleedings are reported in women between 20 and 73 years of age [1-3]. Other authors report cases of nontraumatic subperiosteal orbital hemorrhage caused by anxiety attack, presumably due to increased intracranial pressure due to yelling and crying [3], and scuba diving [9] (although 
this might be due to suction of contents from the mask), and few of them are due to strangulation $[1,2,5,6]$.

The reason why in some reports, strangulation provokes a unilateral [7] or bilateral hemorrhage [5] is unknown. In our patient, the hemorrhage was unilateral. It is probable that due to the position of the patient, the pressure provoking the congestion is different. It might be that those lying down tend to present a unilateral lesion (as in our case and in the case described by Knox Cartwright et al. [6]) and those hanging have a bilateral lesion due to bilateral pressure induced by body weight [5].

Symptoms and signs vary as well. The only sign commonly found is proptosis and movement restriction, although some patients present epistaxis [1,5], dyschromatopsia, or pupillary afferent defect, commonly related to an underlying bleeding disorder [1, 2]. Symptoms commonly found are diplopia, although some cases reported pain and decrease in visual acuity [1,2]. In the case of strangulation, it is common to see ecchymoses [3, 5] and swelling of the conjunctiva as well. In our patient, petechiae were not observed.

Treatment options vary depending on the degree of compression of orbital contents and optic nerve and circulation status of the retina. For our patient, as for many others found in the literature $[1,2]$, we decided on a conservative treatment since the optic nerve and perimetry were unaffected and funduscopic findings were physiologic. In some more extreme cases of proptosis, canthotomy [6], drainage [1, 7], decompressive surgery, or cortisone therapy due to inflammatory causes $[1,3]$ would be indicated. This may apply as well for newborns [1] since the orbit is of smaller size and therefore, the surgical treatment would be indicated, as it would be in other types of intraorbital mass [10-12].

\section{Conclusion}

Subperiosteal bleedings of nontraumatic etiology are uncommon. In this case, when no involvement of intraorbital structures such as the optic nerve are presented, no change in intraocular findings, no pathological perimetric findings are observed, and no anticoagulants are taken, a conservative treatment (wait-and-see) is recommended.

\section{Statement of Ethics}

This report was published with the permission and informed consent of the patient.

\section{Disclosure Statement}

None of the authors has any conflicts of interest.

\section{References}

-1 Atalla ML, McNab AA, Sullivan TJ, Sloan B: Nontraumatic subperiosteal orbital hemorrhage. Ophthalmology 2001;108:183-189.

-2 McNab AA: Nontraumatic orbital hemorrhage. Surv Ophthalmol 2014;59:166-184.

-3 Swanenberg IM, Rizzuti AE, Shinder R: Spontaneous subperiosteal hematoma precipitated by anxiety attack. Orbit 2013;32:402-404. 


\section{Case Reports in Ophthalmology}

\begin{tabular}{l|l}
\hline Case Rep Ophthalmol 2017;8:232-236 \\
\hline DOI: 10.1159/000469701 & $\begin{array}{l}\text { (c) 2017 The Author(s). Published by S. Karger AG, Basel } \\
\text { www.karger.com/cop }\end{array}$ \\
\hline
\end{tabular}

Subiras et al:: Spontaneous Unilateral Subperiosteal Hematoma in the Orbit due to SelfInduced Asphyxia: Unusual Cause of Unilateral Exophthalmos

4 Duke-Elder S: Haemorrhage in the orbit; in Duke-Elder S (ed): System of Ophthalmology. London, Henry Kimpton, 1974, vol 13, p 819e2.

-5 Sakurai K, Morita S, Otsuka H, Sugita M, Taira T, Nakagawa Y, Inokuchi S: Non-traumatic bilateral orbital subperiosteal hematoma in a person who attempted suicide by hanging. Tokai J Exp Clin Med 2014;39:103-105.

6 Knox Cartwright NE, Hussin HM, Suman B, Majid MA, Potts MJ, Kabala J, Mayer EJ: Subperiosteal orbital hemorrhage following self-strangulation. Annals Ophthalmol 2007;39:345-347.

7 Corl K, Hoffmann RJ, Sutton E: Non-traumatic orbital hemorrhage. J Emerg Med 2010;38:378-380.

-8 Katz B, Carmody R: Subperiosteal orbital hematoma induced by the Valsalva maneuver. Am J Ophthalmol 1985;100:617-618.

-9 Gomez-Ledesma I, Mencia-Gutierrez E, Gutierrez-Diaz E, Alonso-Santiago MA: Orbital subperiosteal hemorrhage while scuba diving. Orbit 2006;25:19-22.

10 Avgitidou G, Koch KR, Cursiefen C, Heindl LM: Current aspects of eyelid, lacrimal and orbital surgery in childhood. Ophthalmologe 2015;112:102-109.

11 Lentzsch AM, Goebel H, Heindl LM: Primary orbital hydatid cyst. Ophthalmology 2016;116:1410.

12 Holbach LM, Heindl LM, Guthoff RF: Orbit; in Naumann GOH, Holbach LM, Kruse FE (eds): Applied Pathology for Ophthalmic Microsurgeons. Berlin, Springer, 2008, pp 49-66.
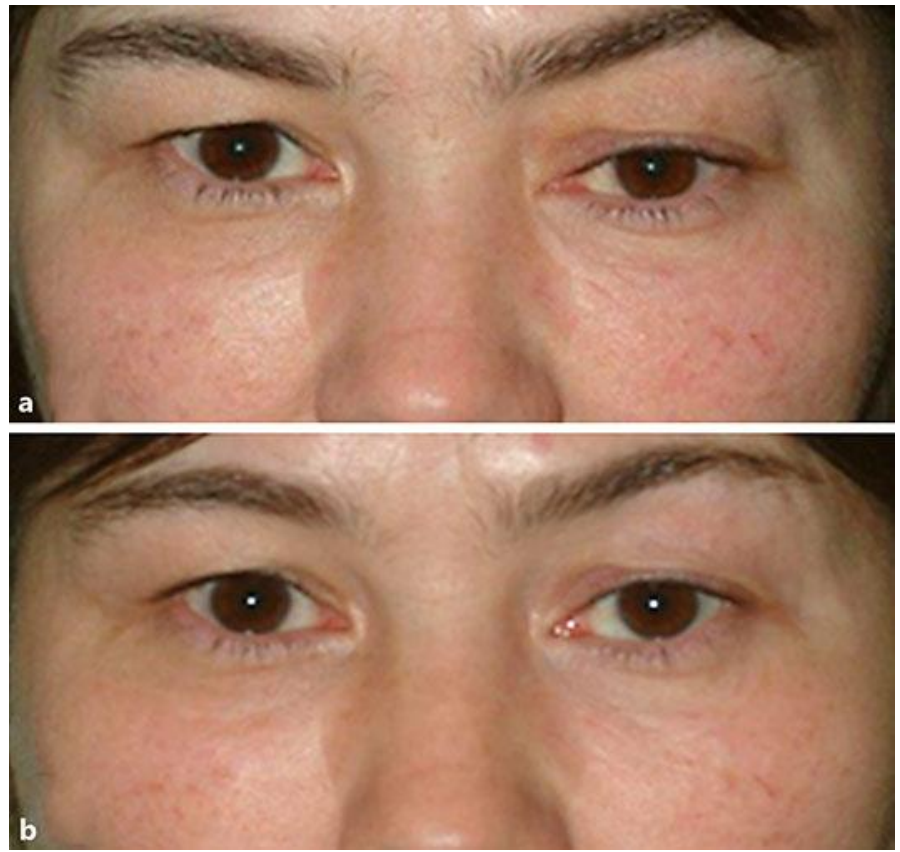

Fig. 1. Clinical appearance of the proptosis and downward displacement of the left globe, at the time of presentation (a) and by the second visit (b). 
Subiras et al.: Spontaneous Unilateral Subperiosteal Hematoma in the Orbit due to SelfInduced Asphyxia: Unusual Cause of Unilateral Exophthalmos
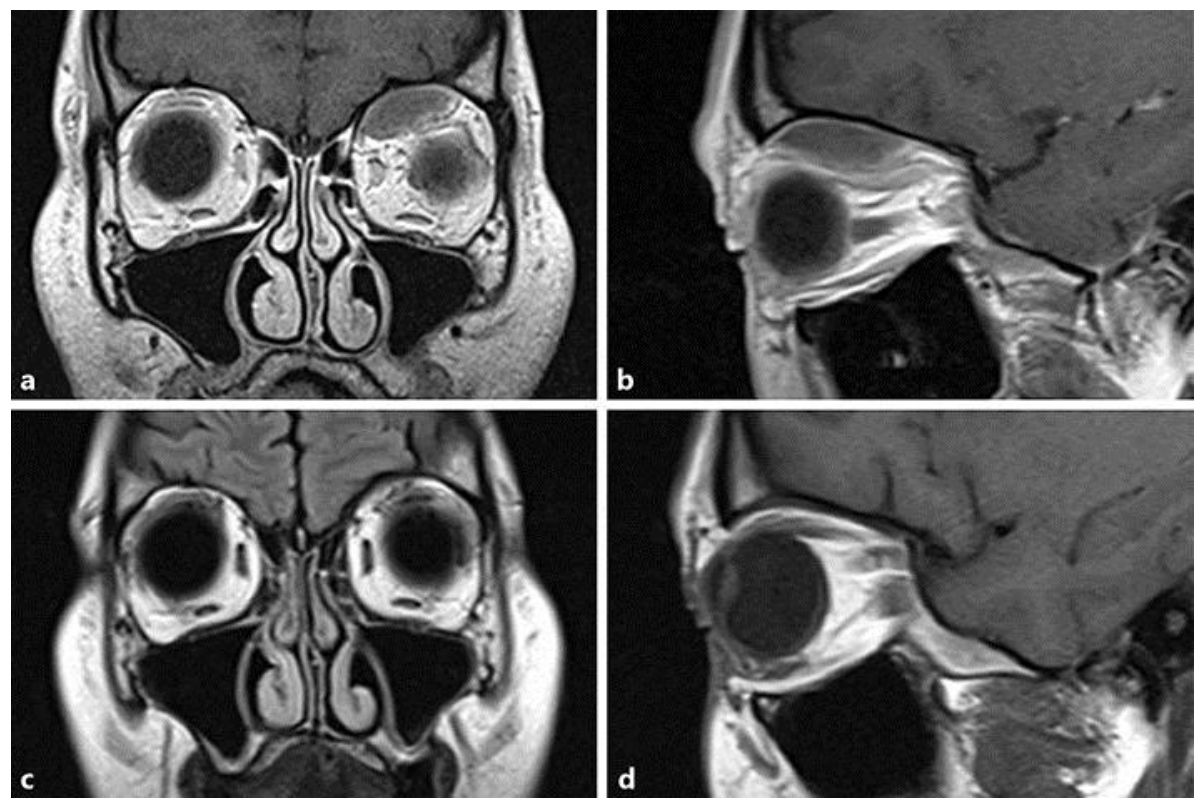

Fig. 2. Coronal (a) and sagittal (b) T1-weighted MRI identifying a biconvex lesion in the superior medial orbital roof with compression of superior muscles. Frontal (c) and sagittal (d) T1-weighted FLAIR views 4 months later with complete resolution of the lesion. 